\title{
ANDROID BASED APPLICATION FOR WIRELESS CONTROL OF WHEELCHAIR
}

\author{
Archana Hule ${ }^{1}$, Rekha Bandage ${ }^{2}$, Pratik Shah ${ }^{3}$, Rashmi Mahajan ${ }^{4}$ \\ ${ }^{l}$ Student, ENTC, Dr.D.Y.Patil School Of Engineering, Maharashtra, India \\ ${ }^{2}$ Student, ENTC, Dr.D.Y.Patil School Of Engineering, Maharashtra, India \\ ${ }^{3}$ Professor, ENTC, Dr.D.Y.Patil School Of Engineering, Maharashtra, India \\ ${ }^{4}$ Professor, ENTC, Dr.D.Y.Patil School Of Engineering, Maharashtra, India
}

\begin{abstract}
The wide spread prevailing loss of limbs is day-to-day scenario due to wars, accidents, age and health problems [2]. A wheelchair monitored with the Android mobile application is developed to help the disabled patients by using application to control the movement of wheelchair in different directions. A help SOS section is incorporated in the application so that incase of any emergency help the person can just enter the number starting with the India country code. The main advantage is to design a wheelchair that will be controlled wirelessly and will be very easy to operate it with no physical efforts [1]. This application will be a boon for many patients who are dependent on wheelchair for their mobility. This project will help the disabled to operate the wheelchair on their own.
\end{abstract}

Keywords: Android mobile phone, Bluetooth module Wheelchair, Accelerometer, Pic 16F877A Microcontroller, DC Motor.

$* * *$

\section{INTTRODUCTION}

Patients involved in physical injuries and disabilities with good mental strength struggle to get through places using the conventional hand powered wheelchair. This paper enables an economic assembly in any existing wheelchair that enables a smart system for automated motion which can be controlled by any Smartphone. The main concept involved is 'Smartphone' which has an operating system as Android which have inbuilt 3 axis accelerometer and Bluetooth Wireless technology [1]. The purpose of our project can be extended to other mobile devices which has Android powered mobile phone by sharing the application that we have developed. The main second part of our system architecture has a microcontroller PIC16F877 which drives the various directions of the $\mathrm{dc}$ motor for directional movement of wheelchair and powers the DC motor for linear motion of the wheelchair [2]. The DC motor controls the front wheels for turning the wheelchair while the pair of DC motor connected to the rear wheels enable linear motion.

\section{LITERATURE SURVEY}

By referring to a study conducted by World Health Organization [3], nearly every one person in fifty is suffering from paralysis due to damaging of nervous system. The causes of paralysis are mainly due to spinal cord injury, strokes and cerebral palsy. The graph titled "PROPORTION OF DISABLED POPULATION BY RESIDENCE INDIA: 2001-11" describes percentage of disabled persons in India has increased both in rural and in urban areas during last decade.

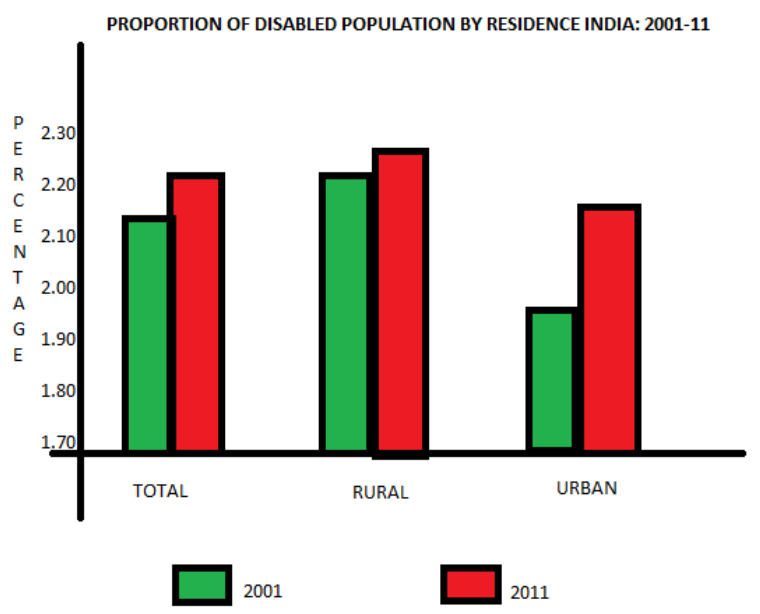

The paralyzed person gets restricted to wheelchair and become dependent on other humans for their movement and daily needs. Many attempts have been made to customize the wheelchair by adding accessories to the wheelchair. The existing wheelchair in market like voice controlled wheelchair, joystick wheelchair and head control wheelchair have some or other drawbacks such as environmental disturbances, mechanical problems or expensive. So in this paper we have made the disabled people independent so that they are free to move on their own wish and need. The complexity is decreased and hardware requirement is also less. 


\section{SYSTEM ARCHITECTURE}

\subsection{Transmitting Unit}

The Android Mobile is used as input. The Application is developed on the Android platform. The graphical user interface provides the user with direction options and an SOS help section. When the application (app) is opened at that time a notification comes to turn on the mobile Bluetooth. When the user touches the virtual button at that time a string is passed that and then transmitted from the transmission unit to the receiving section through the mobile phone's Bluetooth.

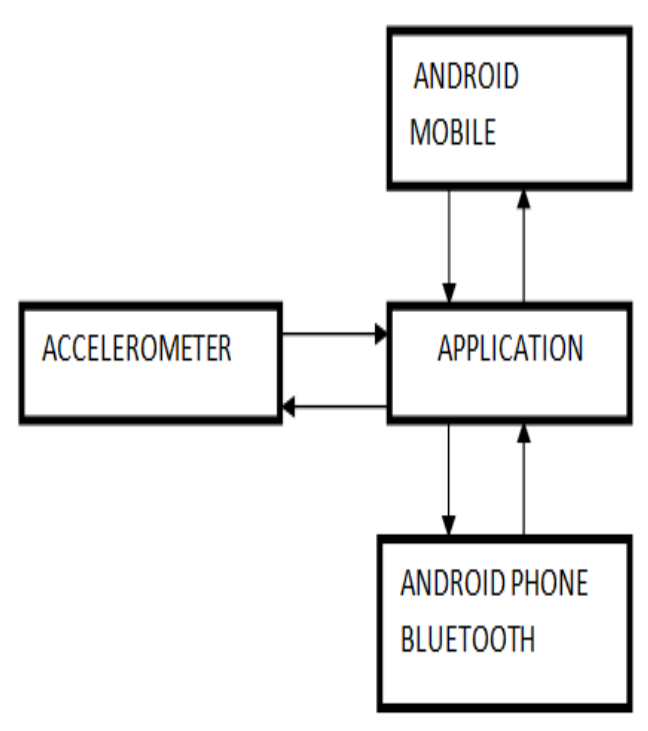

At the receiving end the Bluetooth $\mathrm{HC}-05$ accepts the string and sends it to the Microcontroller PIC16F877 which is a 40 pin programmable interrupt microcontroller. It operates on $5 \mathrm{~V}$ supply and has clock cycle of $20 \mathrm{MHz}$.

\subsection{Receiving Unit}

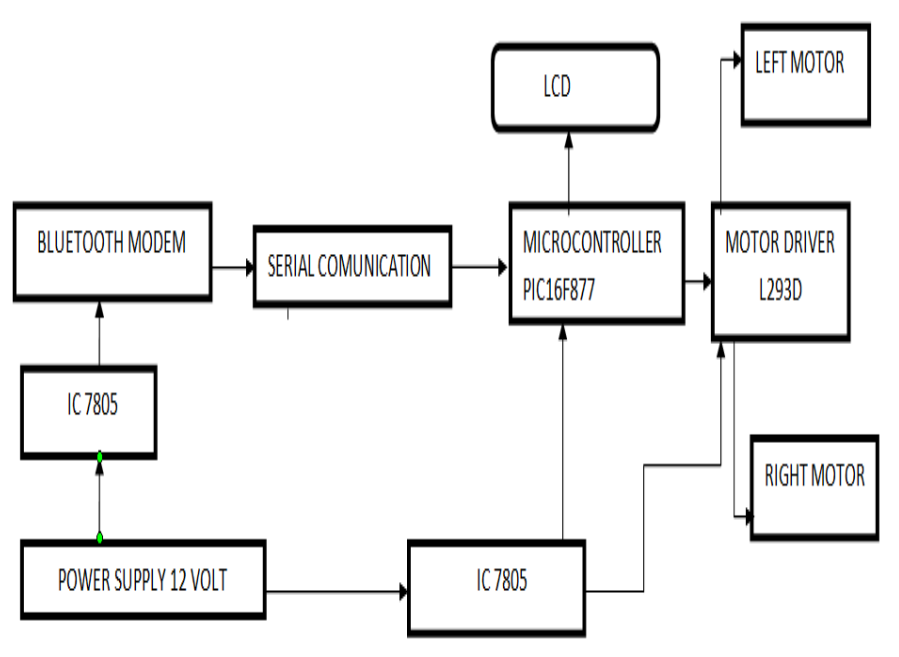

The microcontroller converts the string into ASCI code and then this code is decoded and according to it the motors are given supply and turned to have linear motion of the wheelchair. Bluetooth module is used for wireless transmission of data, operated on $5 \mathrm{~V}$. Battery of $12 \mathrm{~V}$ is used to drive the wheelchair. Battery is used for the purpose of mobility. DC motors are driven by L293D driver IC. L293D is a dual bridge IC. For forward movement the motors are moved forward and for reverse movement the motors are moved in backward direction. For left movement the left motor is stopped and right motor in forward direction and for right movement the right motor is stopped and left motors are moved in forward direction.

\section{FLOWCHART}

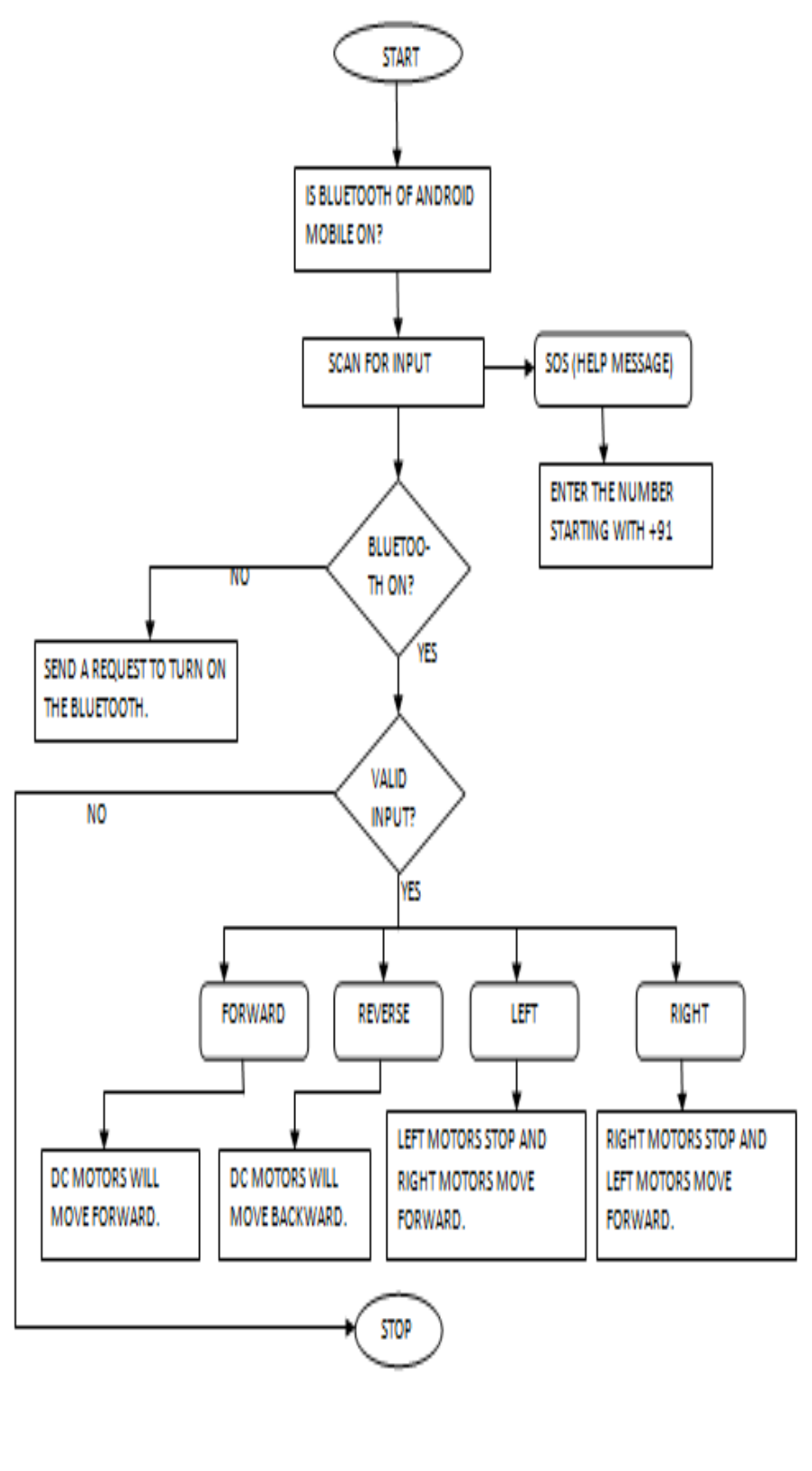




\section{ALGORITHM}

$>$ When the application is opened at that time a request is generated if the Bluetooth is not turned on.

$>$ A connect virtual button is present which is used to connect the Android mobile phone with the hardware Bluetooth HC-05 for wireless transmission of data.

$>$ When the Bluetooth is switched on the application scans the input when the user touches the virtual button.

$>$ If the requirement is forward then all the dc motors are supplied with $5 \mathrm{~V}$ and moved in forward directions for linear movement.

$>\quad$ If the requirement is reverse then all the dc motors are supplied with $5 \mathrm{~V}$ and moved in backward directions for linear movement.

$>$ If the requirement is to turn left then the left dc motors are stopped and the right dc motors are supplied with $5 \mathrm{~V}$ and the wheelchair moves in left direction.

$>$ If the requirement is to turn right then the right $\mathrm{dc}$ motors are stopped and the left dc motors are supplied with $5 \mathrm{~V}$ and the wheelchair moves in right direction.

$>$ If the stop virtual button is touched then all the dc motors are stopped.

$>$ A help virtual button is also present in order to send an SOS message to the concern person in case of any help.

$>$ When the person reaches his/her destination at that time the disconnect virtual button needs to be touched so that the wireless connection is turned off.

\section{ADVANTAGES}

$>\quad$ Easy to drive with negligible efforts.

$>$ Less complexity and less hardware to mount.

$>$ Can be mounted on the existing wheelchair.

$>$ Wireless control helps to monitor the wheelchair easily.

$>$ Reduces manpower and dependency on other human drive.

$>$ Wheelchair is compact and economical.

$>$ Android application can scan the valid input at a faster rate and hence control the movement of wheelchair.

$>$ Provides easy movement for physically challenged people.

$>$ Easy to develop an existing wheelchair and does not require any sophisticated components.

$>$ Low power consuming and easy to operate the wheelchair.

\section{CONCLUSION}

> The project implementation will help all the people who are dependent on wheelchair for their mobility.

$>$ All common man can reach out for this wheelchair to become independent if they hold a smart phone.

$>$ The application built can be useful for many android phones.

$>$ Wheelchair is simple to operate and does not need any external help

\section{FUTURE SCOPE}

Using gear box we can produce a high speed moving wheelchair. PWM modulation can also increase the speed. Solar panel can also be used to charge the battery for powering supply to the components required to drive the wheelchair.

\section{REFERENCES}

[1] "Android Based Mobile Drive System" by Dr. Sheilfali Gupta, Anand Bansal, Deeksha, Harshdeep Singh, Janender Bansal "International Journal of Electronics \& Computer Science Engineering" Volume 3.

[2] "Touch Screen Based Wheelchair System" by Vasundhara G.Posugade, Komal K.Shedge,Chaitali S.Tikhe "International Journal Of Engineering Research and Applications "Volume 2, Issue 2, MarApr-2012.

[3] "Voice operated wheelchair" by Jayesh K.Kokate,A.M.Agarkar "international Journal of research in engineering and technology" Volume 3,Issue 2,Feb-2014.

[4] Basics of developing android application on http://developer.android.com/training/basics/

[5] Android Programmers Guide by Jerome DiMarzio.

\section{BIOGRAPHIES}

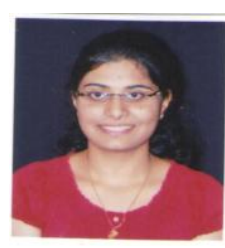

Archana Hule, Student of B.E (E\&TC) of Dr.D.Y.Patil School Of Engineering, Pune.

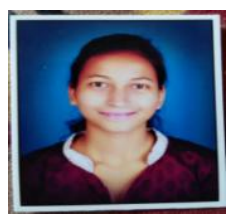

Rekha Bandage, Student of B.E (E\&TC) of Dr.D.Y.Patil School Of Engineering, Pune. 